\title{
Lung function from infancy to school age in cystic fibrosis
}

\author{
Caroline S Beardsmore
}

\begin{abstract}
The aim was to investigate pulmonary mechanics in patients with cystic fibrosis during infancy and again in early childhood to see whether infant tests predicted status at school age. Plethysmographic measurements of thoracic gas volume and airways resistance were made in 29 patients at 6 months and again at 5 years 10 months. Maximum flow at functional residual capacity was measured during infancy for comparison with maximum expiratory flow rates during childhood. While many patients had normal measurements during infancy, pulmonary function had deteriorated by school age. Thoracic gas volume at school age was significantly related to the values in infancy, but other measurements made during childhood were independent of infant values. The relations between measurements in infancy and early childhood described here provide a background against which the role of external factors on pulmonary function in young children with cystic fibrosis can be investigated. (Arch Dis Child 1995; 73: 519-523)
\end{abstract}

Keywords: thoracic gas volume, airways resistance, flow-volume curve.

The assessment of pulmonary function is regarded as essential in the management of cystic fibrosis. The nature and frequency of assessment will vary from centre to centre and may also vary between patients. In an individual, measurements can provide information about the extent of abnormality, progression of disease, and individual response to treatment.

Although tests of pulmonary function made on one single occasion will provide a snapshot of the degree of respiratory impairment, serial testing can reveal trends. This has been employed in long term studies looking at the progression of disease in older children and adults ${ }^{1}$ and in research into the effect of infections and exacerbations of lung function. ${ }^{2-5}$ In addition, repeated testing has been used to look at the effect of bronchodilators, ${ }^{6}$ antibiotics, ${ }^{7}$ and DNase $^{8}$ on pulmonary function.

Measurements of pulmonary function in infants are less commonly undertaken than in older subjects because of the expense of equipment, the need for extensive training of staff, and the requirement for sedation for some investigations. However, the patterns of change and the response to treatment have been described in several studies. ${ }^{9-14}$
The opportunities for comparing measurements made in infancy with those in later childhood have been limited, and the types of investigations at different ages may not be strictly comparable. ${ }^{15}$ The aim of this study was to investigate pulmonary mechanics in a group of patients with cystic fibrosis during infancy and again in early childhood, in order to see whether infant tests could predict pulmonary function at school age. This study also enabled changes in respiratory function to be documented over a period of rapid lung growth and development during which the opportunity for testing is normally extremely limited.

\section{Methods}

SUBJECTS

The subjects were 29 patients ( 17 females, 12 males) with cystic fibrosis born between July 1984 and March 1989. Nineteen were diagnosed on neonatal screening and 18 of these participated in a trial of antibiotic treatment which has been reported elsewhere. ${ }^{141617}$ The remaining 10 infants were diagnosed either because of a known family history of cystic fibrosis (two cases) or because of their clinical presentation. Seven of the eight cases who presented clinically were diagnosed before the age of 9 months but in the remaining case diagnosis was delayed until 19 months. In all 29 cases the diagnosis was confirmed by sweat test.

Measurements of lung mechanics were made during infancy at median age of 6 months (range 1-24) and again in early childhood at median age 5 years 10 months (range 4 years 10 months to 7 years 5 months). During the recruitment period an additional 10 patients with cystic fibrosis had measurements of infant lung mechanics. These patients did not return for later testing because of death (three cases), delayed development and inability to cooperate with testing (one case), or because adverse social circumstances or removal precluded return for follow up.

Following diagnosis all the patients received care from their local consultant paediatricians and all were treated with dietary supplements and physiotherapy. Eleven of the 18 infants who participated in the trial of antibiotic treatment received continuous flucloxacillin (250 $\mathrm{mg}$ twice daily) for the first 2 years of life. All other patients received antibiotics as clinically indicated.

MEASUREMENT OF INFANT LUNG MECHANICS The procedures of measuring infant lung mechanics have been described previously. ${ }^{14}$
Correspondence to: Dr Beardsmore.

Accepted 18 August 1995 
A routine questionnaire was completed and tests were explained in detail to the parents. Infants were sedated with chloral hydrate (up to $100 \mathrm{mg} / \mathrm{kg}$ body weight). Measurements of maximum expiratory flow at functional residual capacity $\left(V_{\max } F R C\right)$ were made using the 'squeeze' or rapid thoracoabdominal compression technique. ${ }^{18}$ Thoracic gas volume and airways resistance (Raw) were measured in an infant whole body plethysmograph using standard techniques. ${ }^{19}$ Data were collected onto computer and values of $\mathrm{V}_{\max } \mathrm{FRC}$, thoracic gas volume, and airways resistance were calculated after completion of the tests. $V_{\max }$ FRC was taken as the flow rate achieved during the forced expiration at a volume equivalent to the resting end expiratory level. The final value used was the highest value obtained from a technically satisfactory manoeuvre.

Wherever possible, measurements of thoracic gas volume were the mean values taken from at least five separate periods of airway occlusion, calculated according to standardised techniques. ${ }^{19}$ Measurements of airways resistance were taken over the initial two thirds of inspiratory flow, and in most instances were the mean of at least 10 breaths taken from two or three separate, technically satisfactory recordings of Raw.

Each measurement for each infant $\left(\mathrm{V}_{\max } \mathrm{FRC}\right.$, thoracic gas volume, and Raw) was then expressed as a score to facilitate analysis. A predicted value for each measurement could be made for each infant on the basis of body length, and the score was the number of standard errors of prediction by which the measured value differed from the prediction. ${ }^{20}$ Scores close to zero indicate that the measured value is close to predicted. Scores between -2 and +2 are considered to fall between normal limits, whereas more extreme scores indicate that the measured value differs significantly from the predicted value.

In several cases two sets of infant pulmonary function tests were performed within the first year of life. The first set of data has been used for comparison with data obtained at school age in 22 patients. In the remaining seven patients the second infant test has been used because the data were more complete or technically superior to those obtained on visit 1 .

\section{MEASUREMENTS OF LUNG MECHANICS AT}

SCHOOL AGE

Patients returned to the respiratory laboratory after approximately five years for repeat testing. Children were weighed and measured and a brief questionnaire was completed. Measurements of forced vital capacity (FVC), forced expired volume in one second $\left(\mathrm{FEV}_{1}\right)$, and maximum expiratory flow at $50 \%$ and $25 \%$ vital capacity $\left(\mathrm{MEF}_{50}, \mathrm{MEF}_{25}\right)$ were measured using a simple screen pneumotachograph. Children were studied while sitting upright and wearing a noseclip. Signals were recorded onto a storage oscilloscope and subsequently plotted at slow speed onto a chart recorder and analysed by hand. One child performed only two full forced expiratory manoeuvres but in all other cases at least three technically satisfactory recordings were made and analysed according to ATS criteria. ${ }^{21}$

Measurements of thoracic gas volume and airways resistance were made with the child seated within a whole body plethysmograph (Jaeger) which incorporated a heated, humidified rebreathing system, thereby avoiding the need for panting. Measurements were taken by hand from chart recordings, and mean values for airways resistance and thoracic gas volume were calculated. Raw was measured from the linear portion of the pressure-flow curve. The mean (SD) number of breaths for airways resistance analysis was $6.7(2 \cdot 2)$ and for thoracic gas volume analysis, $6 \cdot 9(2 \cdot 3)$.

All measurements were compared with predicted values based on height and expressed as SD scores. ${ }^{22-25}$

\section{ANALYSIS OF RESULTS}

The scores obtained for thoracic gas volume and airways resistance during infancy and childhood were directly comparable. The measurement of $\mathrm{V}_{\max } \mathrm{FRC}$ has no direct equivalent in the data obtained at school age but was obtained at a lung volume close to $\mathrm{MEF}_{50}$ and $\mathrm{MEF}_{25}$, both of which can be used for comparison. Changes in the scores between tests in infancy and childhood were assessed using $t$ testing. Linear regression analysis was performed to investigate the relationships between measurements made at the two different ages.

The scoring system for infant data was based on standard errors of prediction, whereas that for data at school age was a standard deviation score. A score based on standard errors of prediction takes account of the variability in the estimated trend line as well as variability in the population. However, unless the sample size of the reference population is small, or the experimental data require extrapolation from the reference population, the two systems give very similar scores, and direct comparison between the measurements at two ages was therefore possible.

\section{Results}

During infant testing, technically satisfactory recordings of Raw were not available in six cases and $V_{\max } F R C$ was not measured in two cases. When tested at school age, two children were not prepared to enter the plethysmograph and four others could not perform consistent forced expiratory manoeuvres. Twenty six pairs of data were available for comparison of thoracic gas volume, and 20 pairs for airways resistance. $\mathrm{V}_{\max } \mathrm{FRC}$ could be compared with $\mathrm{MEF}_{50}$ and $\mathrm{MEF}_{25}$ in 23 and 25 cases respectively.

\section{CHANGES IN LUNG MECHANICS WITH TIME}

Mean results for all measurements are shown (table). During infancy, the mean score for thoracic gas volume fell close to zero, with only one infant having a score below -2 and three infants having measurements above +2 . 
Lung function scores in infancy and at school age

\begin{tabular}{|c|c|c|c|c|c|c|c|}
\hline & \multicolumn{3}{|l|}{ Infancy } & \multicolumn{3}{|l|}{ School age } & \multirow[b]{2}{*}{$M E F_{25}$} \\
\hline & $T G V$ & Raw & $V_{\max } F R C$ & $T G V$ & Raw & $M E F_{50}$ & \\
\hline $\begin{array}{l}\text { No } \\
\text { Mean score } \\
95 \% \text { CI }\end{array}$ & $\begin{array}{l}28 \\
0.306 \\
-0.286 \text { to } \\
0.898\end{array}$ & $\begin{array}{l}23 \\
-0.406 \\
-1.775 \text { to } \\
0.963\end{array}$ & $\begin{array}{l}27 \\
-0.185 \\
-0.700 \text { to } \\
0.358\end{array}$ & $\begin{array}{l}27 \\
2 \cdot 140 \\
1 \cdot 350 \text { to } \\
2.929\end{array}$ & $\begin{array}{l}25 \\
0.417 \\
-0.389 \text { to } \\
1.224\end{array}$ & $\begin{array}{l}25 \\
-1 \cdot 799 \\
-1.794 \text { to } \\
-0.803\end{array}$ & $\begin{array}{l}27 \\
-1 \cdot 797 \\
-2 \cdot 751 \text { to } \\
-0.842\end{array}$ \\
\hline
\end{tabular}

$\mathrm{TGV}=$ thoracic gas volume; $R \mathrm{w}=$ airways resistance; $\mathrm{V}_{\max } \mathrm{FRC}=$ maximum expiratory flow at functional residual capacity; $\mathrm{MEF}_{50}, \mathrm{MEF}_{25}=$ maximum expiratory flow at $50 \%$ and $25 \%$ of vital capacity; $\mathrm{CI}=$ confidence interval.

Airways resistance in infancy was more variable, with seven infants having an apparently low value and five a raised value, though the mean was well within normal limits. Mean $\mathrm{V}_{\max } \mathrm{FRC}$ was also close to prediction, with one infant having a measurement greater than 2 standard errors of prediction and two others having low values.

At the time of school age measurements, the mean value for thoracic gas volume score had risen significantly above zero and 13 patients had measurements above a score of 2 . There had been little change in airways resistance (table), but the two indices of airflow limitation, $\mathrm{MEF}_{50}$ and $\mathrm{MEF}_{25}$, both showed mean values significantly lower than zero. In addition, mean values of FVC and FEV 1 were also significantly reduced when compared with predicted values.

The change in mean thoracic gas volume score between infancy and childhood was statistically significant $(\mathrm{p}<<0.001)$, but that for airways resistance score was not $(p=0 \cdot 29)$. When the mean score for $V_{\max } F R C$ was compared with that for $\mathrm{MEF}_{50}$ and $\mathrm{MEF}_{25}$, significant differences were found $(p=0.0052$ and $p=0.0039$ respectively). Thus over the five year period when measurements were not made, the patients tended to become hyperinflated and to develop small airways dysfunction, although there was no overall change in airways resistance score.

\section{RELATIONS BETWEEN MEASUREMENTS IN}

INFANCY AND AT SCHOOL AGE

The measurement of thoracic gas volume at school age shows a significant linear relationship with that in infancy (fig 1) according to the regression equation:

TGV score $($ childhood $)=1 \cdot 880+0 \cdot 664 \mathrm{TGV}$ score (infancy) $(p=0.006)$

No such relation was found for airways resistance scores $(p=0 \cdot 246)$. When $V_{\max }$ FRC

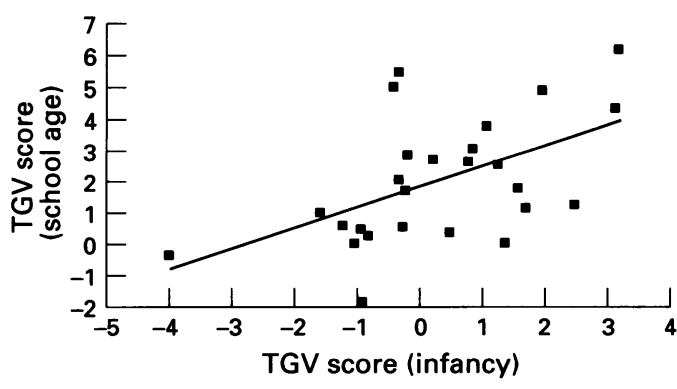

Figure 1 Thoracic gas volume (TGV) score at school age against TGV score in infancy. The regression line is shown $(r=0.525, p=0.006)$. scores were compared with $\mathrm{MEF}_{50}$ or $\mathrm{MEF}_{25}$ scores, although the overall results showed a reduction in small airway function there was no direct relation between the measurement made in infancy and those in childhood $(p=0.997$ and $p=0.265$ respectively) (fig 2 ).

Measurements of FVC and $\mathrm{FEV}_{1}$ are not directly comparable with $\mathrm{V}_{\max } \mathrm{FRC}$, but since both may be indicators of flow limitation they have been compared by linear regression analysis. In neither case was a statistically significant relationship found $(p=0.762$ for $\mathrm{V}_{\max }$ FRC score $v$ FVC score, and $\mathrm{p}=0.910$ for $\mathrm{V}_{\max }$ FRC score $v$ FEV $_{1}$ score).

\section{Discussion}

This study has confirmed that many infants with cystic fibrosis, in a group diagnosed early in life, have normal measurements of lung mechanics. At the age of 5 or 6 pulmonary function had deteriorated, although several children continued to have normal measurements. Thoracic gas volume at school age was significantly related to the value in infancy, but other measurements of lung function made during childhood were independent of infant values. Before considering these findings in greater depth, it is appropriate to consider the limitations of the study.

Plethysmographic measurements of thoracic gas volume and airways resistance were made at both ages using the same techniques. ${ }^{26}$ The assumptions of the technique for measuring thoracic gas volume apply to measurements at all ages. These are (1) accurate transmission of pressure between alveoli and airway opening, (2) isothermal conditions within the lung, (3) absence of airflow within the lung during airway occlusion, and (4) negligible effect of abdominal gas. Older children wore nose clips

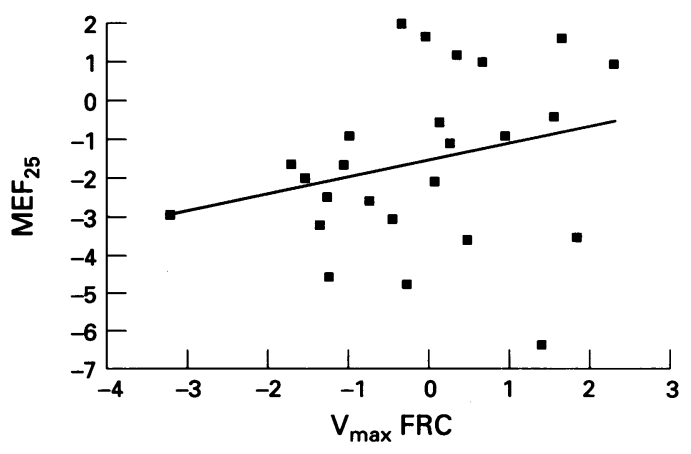

Figure $2 \quad M E F_{25}$ score (maximum expiratory flow at $25 \%$ of vital capacity) at school age against $V_{\max } F R C$ score (maximum expiratory flow at functional residual capacity) in infancy. The regression line is shown $(r=0 \cdot 232, p=0 \cdot 265)$. 
and breathed through rigid mouthpieces, whereas infants breathed through a face mask which fitted around the nose and mouth. Although the face mask may have provided a degree of support to the face, not available to older children, none of the subjects was observed to puff out the cheeks during airway occlusion and therefore loss of pressure transmission in the upper airway was discounted in both groups. The infant test differed from that of the child in that infants were studied while sedated and lying supine, whereas the children were cooperative and sitting upright. Chloral hydrate has been shown not to influence thoracic gas volume measurements in infants. ${ }^{27}$ An effect on lung volume caused by changing from upright to supine posture has been observed in adults. ${ }^{28}$ However, at both ages the results were expressed as a score based on predicted values, which were obtained in the supine position or seated upright for infants and older children respectively. A comparison based on the scores at both ages therefore remains valid.

At both ages the measurement of airways resistance was made during quiet breathing using a heated, humidified rebreathing system. In infant tests the analysis was performed by computer and the reported value was taken over the first two thirds of peak inspiratory flow. During childhood the results were calculated by hand from an $\mathrm{X}-\mathrm{Y}$ chart recording and the measurement was taken over the linear portion of the pressure-flow loop. There were therefore slight differences in the analysis of airways resistance but, again, the scores were calculated on the basis of values obtained in the same manner as the measurements.

The measurements of maximum expiratory flow rates were less straightforward to compare. Although techniques have been described recently which permit forced expiration in infants to begin at lung volumes above end inspiration, ${ }^{29} 30$ the partial expiratory manoeuvre in infants reported here extended from end inspiration to a point below FRC. It was thus not possible to measure forced expired volumes at fixed times (for example, $\mathrm{FEV}_{0.5}, \mathrm{FEV}_{1}$ ) or flow rates at fixed portions of vital capacity (for example, $\mathrm{MEF}_{50}, \mathrm{MEF}_{25}$ ) in the infants. The flow rate which could be measured, $V_{\text {max }} F R C$, is sensitive to changes in end expiratory level and has a wide coefficient of variation. ${ }^{31}$ In older children the measurement of $\mathrm{MEF}_{50}$ and $\mathrm{MEF}_{25}$ generally falls on either side of FRC, if the distribution of lung volumes is normal.

One limitation of this study is that the predicted values for measurements made at school age came from populations of children of height $115 \mathrm{~cm}$ or greater. ${ }^{22-25}$ Within the narrow age range at which the second set of measurements was made there was no relation between age and height . The mean (SD) height of the subjects when studied at school age was 113.8 $(5 \cdot 14) \mathrm{cm}$, with only 12 children being $115 \mathrm{~cm}$ or taller. Thus for over half the group the predicted values were obtained by extrapolation. If the undesirable but necessary process of extrapolation led to an underestimation of predicted thoracic gas volume and overestimations of predicted $\mathrm{MEF}_{50}$ and $\mathrm{MEF}_{25}$, then the observed findings of development of hyperinflation and flow limitation could be artefactual. Also, under circumstances such as these where experimental data are compared with extrapolated data from a reference population, an individual measurement may seem more extreme when assessed on an SD score than one based on standard errors. However, there were no differences in the SD scores for any of the measurements between children of greater or less than $115 \mathrm{~cm}$ height and the decline in lung function with time is therefore unlikely to be artefactual.

Few studies have compared measurements of lung function in infancy with those in later childhood. One previous study has examined 27 subjects of very low birth weight with varying amounts of neonatal lung disease who were restudied at 9 years of age. ${ }^{32}$ In contrast with the present study, no relationship was found between thoracic gas volume measured in infancy and any aspect of plethysmography or spirometry at school age. Furthermore, airways conductance (Gaw) (which is the reciprocal of Raw) measured at 4-12 months correlated strongly with several aspects of lung function in childhood, ${ }^{32}$ again contrasting with the present findings. However, the expected patterns of change in lung function in the two study groups are different. Infants of low birth weight with neonatal lung disease have early abnormalities of lung function ${ }^{33}$ but, although some abnormalities may still be detectable in childhood, ${ }^{34} 35$ the capacity for catch up growth and repair of the lung is such that overall improvement might be expected. Infants with cystic fibrosis may have lung function which is normal initially, as in the present study population where over two thirds were diagnosed very soon after birth, but thereafter measurements show gradual deterioration.

The variability of measures of lung function may have contributed to the observations in the present study. In older patients with cystic fibrosis it has been shown that routine spirometric measurements show greater withinsubject variation than in healthy controls, whereas plethysmographic measures of lung volumes do not. ${ }^{36}$ This may explain in part the lack of correlation between $\mathrm{V}_{\max } \mathrm{FRC}$ and $\mathrm{MEF}_{50}$ or $\mathrm{MEF}_{25}$.

Several external factors have been shown to influence the clinical course in patients with cystic fibrosis. These include bacterial infections (notably with Pseudomonas aerugi$n o s a)^{37}$ and exposure to environmental tobacco smoke. ${ }^{38}$ It is reasonable to speculate that the number and severity of respiratory infections and the amount of physiotherapy may also affect both the clinical course and the measurements of lung function in these patients. An examination of the precise role of these factors is beyond the scope of the present study. However, this study has examined children with cystic fibrosis unselected except by virtue of early diagnosis, and shown a unique relation between lung volume measurements in infancy and at age 5 or 6 . Investigations into the role of 
external factors on lung function in young children with cystic fibrosis can be made against this background.

I thank Dr John Thompson for statistical advice, and Professors Hamish Simpson and Michael Silverman for helpful discussion. I should like to express my gratitude to Anne Williams, Kieran McArdle, and Kerry Poole for technical assistance and to the consultants and families of all children involved in the study. Some of the measurements reported here formed part of an MRC funded trial of antibiotic therapy.

1 Corey M, Levison H, Crozier D. Five- to seven-year course of pulmonary function in cystic fibrosis. Am Rev Respir Dis 1976; 114: 1085-92.

2 Loening-Baucke VA, Mischler E, Myers MG. A placebocontrolled trial of cephalexin therapy in the ambulatory management of patients with cystic fibrosis. $¥$ Pediatr 1979; 95: 630-7.

3 Hordvik NL, Konig P, Hamory B, et al. Effects of acute viral respiratory tract infections in patients with cystic fibrosis. Pediatr Pulmonol 1989; 7: 217-22.

4 Gozal D, Bailey SL, Keens TG. Evolution of pulmonary function during an acute exacerbation in hospitalised function during an acute exacerbation in hospitalised patients

5 Rosenberg SM, Schramm CM. Predictive value of pulmonary function testing during pulmonary exacerbation in cystic fibrosis. Pediatr Pulmonol 1993; 16: 227-35.

6 Pattishall EN. Longitudinal response of pulmonary function to bronchodilators in cystic fibrosis. Pediatr Pulmonol 1990; 9: 80-5.

7 Steinkamp G, Tummler B, Gappa M, et al. Long-term tobramycin aerosol therapy in cystic fibrosis. Pediatr Pulmonol 1989; 6: 91-8.

8 Ramsey BW, Astley SJ, Aitken ML, et al. Efficacy and safety of short-term administration of aerosolised recombinant human deoxyribonuclease in patients with cystic fibrosis. Am Rev Respir Dis 1993; 148: 145-51.

9 Phelan PD, Gracey M, Williams HE, Anderson CM. Ventilatory function in infants with cystic fibrosis. Arch Dis Child 1969; 44: 393-400.

10 Tepper RS, Hiatt PW, Eigen H, Smith J. Total respiratory system compliance in asymptomatic infants with cystic system compliance in asymptomatic infants

11 Tepper RS, Hiatt P, Eigen H, Scott P, Grosfeld J, Cohen $M$. Infants with cystic fibrosis: pulmonary function at diagnosis. Pediatr Pulmonol 1988; 5: 15-18.

12 Beardsmore CS, Bar-Yishay E, Maayan C, Yahav Y, Katznelson D, Godfrey S. Lung function in infants with cystic fibrosis. Thorax 1988; 43: 545-51.

13 Hardy KA, Wolfson MR, Schidlow DV, Shaffer TH. Mechanics and energetics of breathing in newly diagnosed infants with cystic fibrosis: effect of combined bronchodilator and chest physical therapy. Pediatr Pulmonol 1989; 6: $103-8$.

14 Beardsmore CS, Thompson JR, Williams A, et al. Pulmonary function in infants with cystic fibrosis: the effect of antibiotic treatment. Arch Dis Child 1994; 71: 133-7.

15 Godfrey S, Mearns M, Howlett G. Serial lung function studies in cystic fibrosis in the first 5 years of life. Arch Dis Child 1978; 53: 83-5.

16 Green MR, Weaver LT, Heeley AF. Prospective study of cystic fibrosis identified by neonatal screening. Arch Dis Child 1993; 68: 464-7.

17 Weaver LT, Green MR, Nicholson K, et al. Prognosis in cystic fibrosis treated with continuous flucloxacillin from the neonatal period. Arch Dis Child 1994; 70: 84-9.

18 Taussig LM, Landau LI, Godfrey S, Arad I. Determinants of forced expiratory flows in newborn infants. $\mathcal{F} A p p l$ Physiol 1982; 53: 1220-7.
19 Stocks J, Levy NM, Godfrey S. A new apparatus for the accurate measurement of airways resistance in infancy. F Appl Physiol 1977; 43: 155-9.

20 Hampton FJ, Beardsmore CS, Morgan W, Williams A, Taussig L, Thompson JR. A scoring system for lung function tests in infants. Pediatr Pulmonol 1992; 14: 149-55.

21 American Thoracic Society. Snowbird workshop on standardisation of spirometry. Am Rev Respir Dis 1979; 119: 831-8.

22 Solymar L, Aronsson P-H, Bake B, Bjure J. Nitrogen singlebreath test, flow-volume curves and spirometry in healthy children, 7-18 years of age. Eur $\mathcal{F}$ Resp Dis 1980; 61: 275-86.

23 Zapletal A, Samanek M, Paul T. Upstream and total airway conductance in children and adolescents. Bull Eur Physiopathol Resp 1982; 18: 31-7.

24 Zapletal A, Paul T, Samenek M. Die Bedeutung Leutiger Methoden der Lungenfunktionsdiagnostik zur Feststellung einer Ogbstruktion der Atemwegebeikindern und Jugendlichen. Z Erkrank Atm-Org 1977; 149: 343-71.

25 Zapletal A, Paul T, Samanek M. Pulmonary elasticity in children and adolescents. F Appl Physiol 1976; 40: 953-61.

26 Dubois AB, Botelho SY, Bedell GN, Marshall R, Comroe JH. A rapid plethysmographic method for measuring thoracic gas volume: a comparison with a nitrogen washout method for measuring functional residual capacity in normal subjects. F Clin Invest 1956; 35: capacity

27 Turner DJ, Morgan SEG, Landau LI, Le Souef PN. Methodological aspects of flow-volume studies in infants. Pediatr Pulmonol 1990; 8: 289-93.

28 Briscoe WA. Section 3 Respiration. In: Fenn WO, Rahn H, eds. Handbook of physiology. Vol 2. Washington DC: American Physiological Society, 1965: 1345-79.

29 Turner DJ, Lanteri CJ, Le Souef PN, Sly PD. Improved detection of abnormal respiratory function using forced expiration from raised lung volume in infants with cystic fibrosis. Eur Respir f 1994; 7: 1995-9.

30 Kerem E, Reisman J, Gaston S, Levison H, Bryan AC. Maximal expiratory flows generated by rapid chest compression following end-inspiratory occlusion or expiratory clamping in young children. Eur Resp $\mathcal{f} 1995$; 8: 93-8.

31 Hanrahan JP, Tager IB, Castile RG, Segal MR, Weiss ST, Speizer FE. Pulmonary function measures in healthy Speizer FE. Pulmonary function measures

32 Chan KN, Wong YC, Silverman M. Relationship between infant lung mechanics and childhood lung function in children of very low birthweight. Pediatr Pulmonol 1990; 8: 74-81.

33 Wong YC, Beardsmore CS, Silverman M. Pulmonary sequelae of neonatal respiratory distress in very low birthweight infants: a clinical and physiological study. Arch Dis Child 1982; 57: 418-24.

34 Coates AL, Bergsteinsson H, Desmond K, Outerbridge EW, Beaudry PH. Long-term pulmonary sequelae of premature birth with and without idiopathic respiratory distress syndrome. F Pediatr 1977; 90: 611-6.

35 Chan KN, Noble-Jamieson CM, Elliman A, Bryan EM, Silverman M. Lung function in children of low birthweight. Arch Dis Child 1989; 64: 1284-93.

36 Cooper PJ, Robertson cystic fibrosis, Hudson IL, Phelan PD. Variability of pulmonary function tests in cystic fibroPD. Variability of pulmonary function
sis. Pediatr Pulmonol 1990; 8: 16-22.

37 Kerem E, Corey M, Gold R, Levison H. Pulmonary function and clinical course in patients with cystic fibrosis after pulmonary colonisation with Pseudomonas aeruginosa. f Pediatr 1990; 116: 714-9.

38 Gilljam H, Stenlund C, Ericsson-Hollsing A, Strandvik B. Passive smoking in cystic fibrosis. Respir Med 1990; 84: 289-91. 